\title{
Cerebrovascular Dynamics During Continuous Motor Task
}

\author{
M. MÜLLER ${ }^{1}$, M. ÖSTERREICH ${ }^{1}$ \\ ${ }^{1}$ Neurocenter, Neurovascular Laboratory, Lucerne Kantonsspital, Lucerne, Switzerland
}

Received February 20, 2019

Accepted July 26, 2019

Epub Ahead of Print October 25, 2019

\section{Summary}

We investigated the cerebral autoregulation (CA) dynamics parameter phase and gain change when exposed to a longlasting motor task. 25 healthy subjects (mean age $\pm \mathrm{SE}$, $38 \pm 2.6$ years, 13 females) underwent simultaneous recordings of spontaneous fluctuations in blood pressure (BP), cerebral blood flow velocity (CBFV), and end-tidal $\mathrm{CO}_{2}\left(\mathrm{ETCO}_{2}\right)$ over 5 min of rest followed by 5 min of left elbow flexion at a frequency of $1 \mathrm{~Hz}$. Tansfer function gain and phase between BP and CBFV were assessed in the frequency ranges of very low frequencies (VLF, 0.02$0.07 \mathrm{~Hz}$ ), low frequencies (LF, 0.07-0.15), and high frequencies $(\mathrm{HF},>0.15)$. CBFV increased on both sides rapidly to maintain an elevated steady state until movement stopped. Cerebrovascular resistance fell on the right side (rest $1.35 \pm 0.06$, movement $1.28 \pm 0.06, \mathrm{p}<0.01)$, LF gain decreased from baseline (right side $0.97 \pm 0.07 \% / \mathrm{mm} \mathrm{Hg}$, left $1.01 \pm 0.09$ ) to movement epoch (right $0.73 \pm 0.08$, left $0.76 \pm 0.06, p \leq 0.01$ ). VLF phase decreased from baseline (right $1.03 \pm 0.05$ radians, left $1.10 \pm 0.06$ ) to the movement epoch (right $0.81 \pm 0.07$, left $0.82 \pm 0.10, p \leq 0.05)$. CA regulates continuous motor efforts by changes in resistance, gain and phase.

\section{Key words}

Cerebrovascular dynamics - Motor task • Transcranial Doppler sonography • Transfer function • Physiology

\section{Corresponding author}

M. Müller, Neurocenter, Kantonsspital Luzern, Spitalstasse, CH-6000 Lucerne, Switzerland. E-mail: Martin.mueller@luks.ch

\section{Introduction}

Cerebral autoregulation (CA) is the ability of the brain vasculature to maintain cerebral blood flow constant over a wide blood pressure (BP) range (Kontos et al. 1978, Harper et al. 1984). When performing cognitive, motor or other tasks the blood supply to the activated brain areas is then further modulated regionally via vasoconstriction and dilation which are based on the metabolic demands. CA is assessable by:

a) static methods which are characterized by measuring cerebral blood flow or its velocity [CBF(V)] under stable conditions before and after a vasodilatory/vasoconstrictory stimulus (Leenders et al. 1999, Paulson et al. 2010, Powers 1991), and

b) by dynamic methods which analyze the interaction between $\mathrm{CBF}(\mathrm{V})$ and $\mathrm{BP}$ at spontaneous or induced slow oscillations present in $\mathrm{CBF}(\mathrm{V})$ and $\mathrm{BP}$ (Claassen et al. 2016, Meel-van den Abeelen et al. 2014, Müller and Österreich 2014, Zhang et al. 1998). When CA fails an additional metabolic mechanism helps to keep oxygen concentration in the needed range by increasing the oxygen extraction rate as increasing the amount of the oxygen concentration released from hemoglobin (Leenders et al. 1999). In pathological conditions such as acute stroke the coordinated overlapping of these mechanisms seems to be disturbed (Caldas et al. 2018, Maggio et al. 2013, Reinhard et al. 2012, Rivera-Lara et al. 2017) which might be relevant for an early start of rehabilitation (Coleman et al. 2017, Li et al. 2018, Chi et al. 2018).

In recent years the dynamics of the cerebrovascular system was studied by means of mathematical models which usually describe the BP CBFV system over a wide range of $\mathrm{BP}$ and $\mathrm{CBFV}$ changes with $\mathrm{CBF}$ regulation occurring mostly between CBFV changes of 5 to 50 seconds (Claassen et al. 2016, Mitsis et al. 2006, Müller and Österreich 2014, Serrador et al. 2005, Zhang et al. 1998.). To characterize the system better its response to physiological stimuli like hand gripping, arm or leg movements, or visual tasks 
(Caldas et al. 2018, Giller et al. 2000, Maggio et al. 2013, Panerai et al. 2012a, Salinet et al. 2013) is analyzed. The duration of the used stimuli is usually short (e.g. a minute or less) and repeated several times to allow for an analysis after averaging over all runs, a setting usually addressing neurovasal coupling (NVC). The characteristic NVC response is a rapid, often bilateral $\mathrm{CBF}(\mathrm{V})$ increase which continues as long as the stimulus is present. As far as it is deducible from such short interventions, $\mathrm{CA}$ in terms of the transfer function (TF) estimates phase and gain is unchanged compared to the baseline prior to the stimulus. Whether these findings are transferrable to continuous tasks is assumed, but not established. The aim of our study was to prove this assumption using as stimulus elbow flexion and extension (at a frequency of $1 \mathrm{~Hz}$ ) as this task has been shown to provide a feasible CBFV increase (Llwyd et al. 2017, Panerai et al. 2012a) that enables to study autoregulatory mechanisms.

\section{Methods}

The study was approved by the ethics committee of Northwest- and Central Switzerland and followed the Declaration of Helsinki as well as good clinical practice standards. Written informed consent was obtained from all subjects $[\mathrm{n}=25$, women 13 , mean age \pm standard error of means (SE) 38 \pm 2.6 years (range 24-62 years)].

Experimental setting: all investigations followed the recommendation of Claassen et al. (2016), were performed in the late morning with the subject in a supine position with the head elevated approximately $30^{\circ}$ in a room with dimed light. Last coffee or tea uptakes were taken a minimum of 4 hours before the investigations. The subjects were dominantly right-handed (20 of 25), all were non-smokers, healthy and without cerebrovascular risk factors. Participants were carefully instructed to flex and extend the elbow over the full movement range (= one movement cycle) at a pace of $1 \mathrm{~Hz}$ which was signaled by a computerized metronome's beep. Before mounting the probes several elbow movement cycles were tried at the metronome's pacing. We assessed the cerebral blood flow velocity (CBFV) in both middle cerebral arteries (MCA) using transcranial Doppler sonography (TCD) by placing the 2-MHz probes of the TCD device (MultidopX, DWL, Compumedics, Sipplingen, Germany) at the temporal skull and fixed them with a head holder provided by the manufacturer. The MCAs were identified as CBFV directed towards the probe/skull in a depth of 50-55 mm. End-tidal $\mathrm{CO}_{2}$ $\left(\mathrm{ETCO}_{2}\right)$ was measured via a small nostril tube with the capnography embedded in the TCD device. BP was estimated by finger plethysmography (Finometer Pro, Finapres Medical Systems, Amsterdam, The Netherlands) placed at the fingertip of the right index finger, special attention was paid to its calibration to the brachial artery pressure. The BP signal was imported into the TCD device, and all parameters were recorded simultaneously. After all probes were placed and the subject familiar with the surroundings and the experimental setting, we started with a baseline recording of $5 \mathrm{~min}$, thereafter the elbow movement paradigm was performed over 5 min.

Data preparation: $\mathrm{BP}, \mathrm{CBFV}$, and $\mathrm{ETCO}_{2}$ data were collected at $100 \mathrm{~Hz}$. The data were analyzed using Matlab (2015b, Math Works Inc., Natick, MA, USA). The data were visually inspected for artefacts, and only artefact-free data periods of 5 min were used. Each raw data time series was averaged over 1 second interval. The coherence and the TF estimates of phase and gain between the BP and the CBFV time series were extracted from their respective power auto-spectra or cross-spectra using Welch's averaged periodogram method, with a Hann window length of $100 \mathrm{~s}$, window overlap of $50 \%$, and a total data length of 300 seconds. In each subject, the coherence, the phase (in radian), and the gain (in $\mathrm{cm} / \mathrm{s} / \mathrm{mmHg}$ and in $\% / \mathrm{mmHg}$ ) were calculated over a frequency range of $0.02-0.40 \mathrm{~Hz}$ in the epochs of baseline and motor task. Based on recent recommendations (Claassen et al. 2016) only those phase and gain values were considered for further use when coherence was $>0.44$. The results of phase, gain and coherence are reported as their respective average in the very low frequency range (VLF, 0.02-0.07 Hz), low frequency range $(\mathrm{LF}, 0.07-0.15 \mathrm{~Hz})$, and high frequency range (HF, 0.15-0.4 Hz). Over each epoch we also calculated the cerebrovascular resistance as mean $\mathrm{BP} /$ mean $\mathrm{CBFV}$, and heart rate which was derived from the BP signal.

\section{Statistical analysis}

Data analysis was performed with the Matlab Statistical Toolbox. Using a Kolmogorov-Smirnov test, all data showed a normal distribution, and the data are reported as mean $\pm \mathrm{SE}$ (standard error of the mean). To compare means between the two epochs (baseline and motor task) we used one-way ANOVA including a correction for multiple comparisons when indicated. $\mathrm{P} \leq 0.05$ was considered statistically significant. 


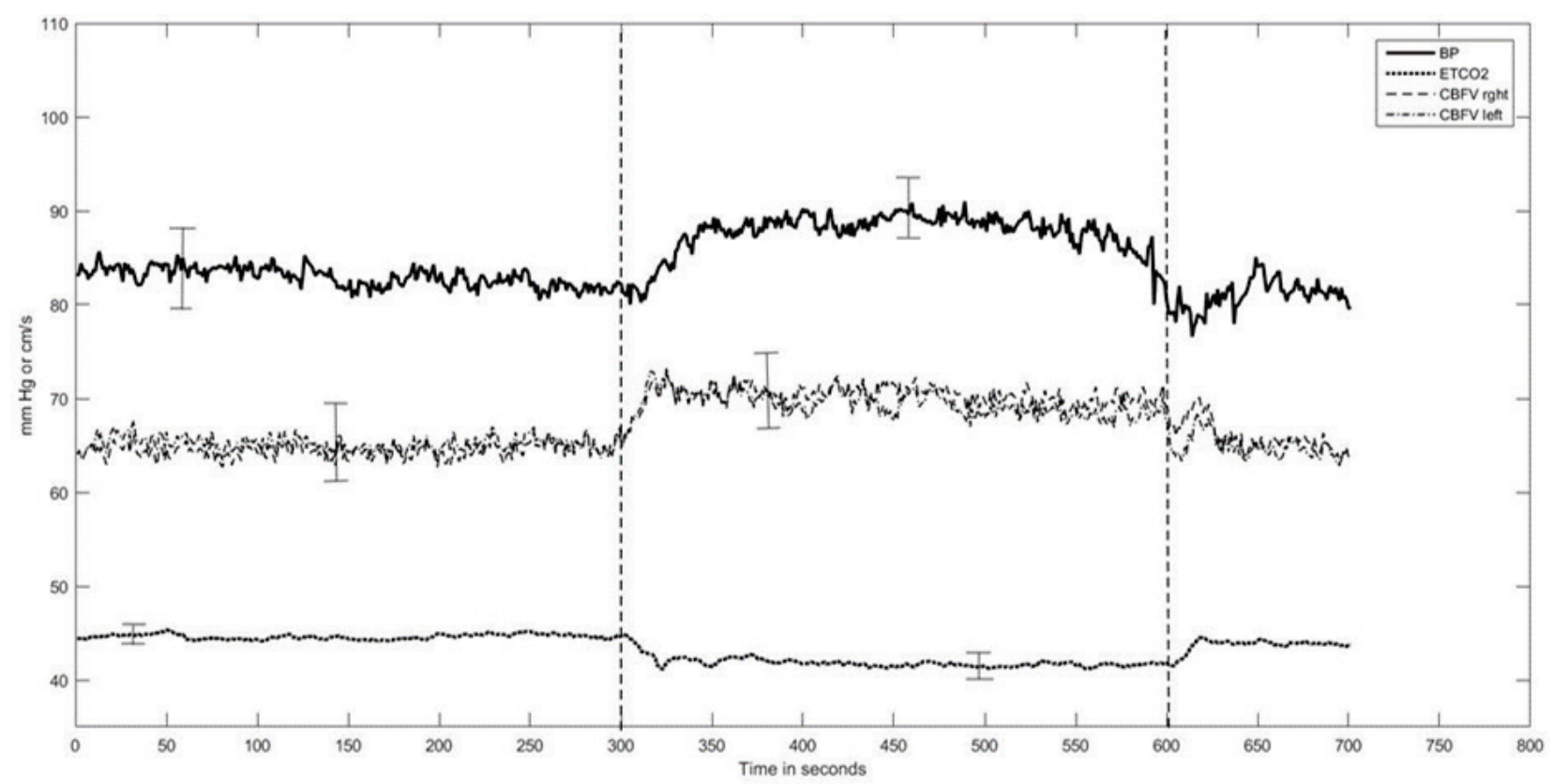

Fig. 1. Time course (group averaged) of blood pressure (BP), end-tidal carbon dioxide $\left(\mathrm{ETCO}_{2}\right)$, and cerebral blood flow velocity (CBFV) in both middle cerebral arteries (MCA). For simplicity, bars indicate the maximum standard error of mean (SE) achieved in the whole epoch (baseline or elbow movement); the SE bar for CBFV represents the SE in both MCAs. The movement epoch is indicated by the dashed perpendicular lines.

Table 1. Hemodynamic baseline variables and results of transfer function estimates at baseline and at elbow movement over 5 minutes at a frequency of $1 \mathrm{~Hz}$.

\section{Baseline}

Mean Blood Pressure ( $\mathrm{mm} \mathrm{Hg}$ )

Mean ETCO2 ( $\mathrm{mm} \mathrm{Hg}$ )

Mean Heart rate (beats/minute)

Mean $C B F V$ right $(\mathrm{cm} / \mathrm{s})$

Mean CBFV left $(\mathrm{cm} / \mathrm{s})$

Mean CVR right $(\mathrm{mm} \mathrm{Hg} / \mathrm{cm} / \mathrm{s})$

Mean CVR left $(\mathrm{mm} \mathrm{Hg} / \mathrm{cm} / \mathrm{s})$

Mean Coherence

- Very low frequency

- Low frequency

- High frequency

Mean Gain (in cm/s/mmHg)

- Very low frequency

- Low frequency

- High frequency

Mean Gain (in \% $\mathrm{cm} / \mathrm{s} / \mathrm{mmHg}$ )

$$
\begin{array}{ll}
\text { - } & \text { Very low frequency } \\
\text { - } \quad \text { Low frequency } \\
\text { - } \quad \text { High frequency }
\end{array}
$$

Mean Phase (radians)

$$
\begin{array}{ll}
\text { - } & \text { Very low Frequency } \\
\text { - } & \text { Low frequency } \\
\text { - } & \text { High frequency }
\end{array}
$$

$83 \pm 2.6$
$44.6 \pm 0.60$
$65 \pm 1.8$
$65 \pm 2.4$
$64 \pm 2.2$
$1.35 \pm 0.06$
$1.32 \pm 0.06$

\section{Right}

$0.46 \pm 0.03$

$0.77 \pm 0.02$

$0.70 \pm 0.02$

Left

$\begin{array}{cc}0.24 \pm 0.05 & 0.23 \pm 0.3 \\ 0.62 \pm 0.05 & 0.63 \pm 0.05 \\ 0.70 \pm 0.07 & 0.65 \pm 0.07\end{array}$

$0.48 \pm 0.03$

$0.75 \pm 0.02$

$0.68 \pm 0.03$

$0.65 \pm 0.07$

$0.37 \pm 0.07$

$0.29 \pm 0.05$

$0.97 \pm 0.07$

$1.01 \pm 0.09$

$1.02 \pm 0.10$

$0.99 \pm 0.09$

$\begin{array}{ll}1.03 \pm 0.05 & 1.10 \pm 0.06 \\ 0.70 \pm 0.06 & 0.67 \pm 0.05 \\ 0.28 \pm 0.10 & 0.28 \pm 0.10\end{array}$

$1.03 \pm 0.05 \quad 1.10 \pm 0.06$

$0.28 \pm 0.10$
Elbow movement

$87 \pm 3.4 \dagger$
$41.7 \pm 0.68 \dagger$
$74 \pm 2.2 \dagger$
$69 \pm 2.4 \dagger$
$70 \pm 2.6 \dagger$
$1.28 \pm 0.06 \dagger$
$1.31 \pm 0.06$

Right

$0.46 \pm 0.03 \quad 0.38 \pm 0.04$

$0.72 \pm 0.03 \quad 0.67 \pm 0.05$

$0.70 \pm 0.03 \quad 0.65 \pm 0.03$

$0.26 \pm 0.04 \quad 0.19 \pm 0.05$

$0.54 \pm 0.06 \quad 0.53 \pm 0.06$

$0.65 \pm 0.08 \quad 0.59 \pm 0.08$

$0.35 \pm 0.06 \quad 0.26 \pm 0.06$

$0.73 \pm 0.08 \dagger \quad 0.76 \pm 0.06 \dagger$

$0.93 \pm 0.10 \quad 0.98 \pm 0.10$

$0.81 \pm 0.07 \dagger \quad 0.82 \pm 0.10 *$

$0.77 \pm 0.05 \quad 0.70 \pm 0.05$

$0.37 \pm 0.11 \quad 0.28 \pm 0.11$

Values are mean $\pm \mathrm{SE} . \mathrm{ETCO}_{2}$, end-tidal carbon dioxide, $\mathrm{CBFV}$, cerebral blood flow velocity, CVR, cerebrovascular resistance, ANOVA: $* p \leq 0.05,+p \leq 0.01$ 


\section{Results}

In 24 of the 25 subjects, recordings were possible in both MCAs. In one person only the right MCA was detected. Artefact-free recordings were achieved from all vessels. Figure 1 shows the time course of mean $\mathrm{CBFV}$ (right $n=25$, left $n=24)$, mean $\mathrm{ETCO}_{2}(\mathrm{n}=25)$ and mean BP $(n=25)$ over the total experiment. After the baseline epoch CBFV increases rapidly with elbow movement and remained at an elevated steady state over the total time of elbow movement, CBFV increase is slightly higher on the right side (contralateral to the arm movement, Table 1). After starting of arm movement $\mathrm{ETCO}_{2}$ and BP decreased $\left(\mathrm{ETCO}_{2}\right)$ or increased (BP). We defined the time point at which $\mathrm{ETCO}_{2}$ decreased or BP increased as the time point at which the decreasing or increasing curve was clearly below or above the fluctuation range of the baseline recording curve. $\mathrm{ETCO}_{2}$ dropped $5 \pm 0.1$ seconds after movement starting from 44.8 to $41.1 \mathrm{mmHg}$ to remain thereafter relatively stable at a mean $\mathrm{ETCO}_{2}$ of $41.7 \mathrm{~mm}$ $\mathrm{Hg}$. In contrast to $\mathrm{CBFV}$ and $\mathrm{ETCO}_{2}, \mathrm{BP}$ remained at the baseline level for the first $20 \pm 0.3$ seconds after starting of the stimulus before rising notably.

Table 1 shows the significant differences between the variables of the baseline and the motor task epochs. BP, CBFV on both sides and heart rate increased while $\mathrm{ETCO}_{2}$ decreased in the motor task epoch. CVR decreased in the right MCA $(p \leq 0.01)$ but not in the left MCA. Coherence and gain (in $\mathrm{cm} / \mathrm{s} / \mathrm{mmHg}$ ) did not show differences between the two epochs within one side nor between the two sides. Gain in $\% / m m H g$ decreased significantly at both sides in the LF range from baseline (right side $0.97 \pm 0.07$, left $1.01 \pm 0.09$ ) to movement epoch (right $0.73 \pm 0.08$, left $0.76 \pm 0.06$. $\mathrm{P} \leq 0.01$ ), it remained unchanged in the VLF and HF ranges. Phase (in radian) in the VLF range decreased significantly from baseline (right $1.03 \pm 0.05$, left $1.10 \pm 0.06$ ) to the elbow movement epoch (right $0.81 \pm 0.07$, left $0.82 \pm 0.10$. $\mathrm{P} \leq 0.05$ ), it did not change in the LF and HF ranges. Heart rate (in heart beat/s) was 1.11-1.15 \pm 0.019 (maximum SE) during the rest period, it was 1.12-1.16 \pm 0.022 between starting elbow movement and 12 seconds thereafter (not significant different), it was $1.38 \pm 0.011 \quad(\mathrm{p}<0.005)$ at 15 seconds after elbow movement start and remained at this level until the end of movement $(1.38 \pm 0.022$, $\mathrm{p}<0.005$ compared to baseline).

\section{Discussion}

The time course of and the amount of the evoked
CBFV achieved by our setting corresponds to other motor tasks evoked flow studies targeting NVC insofar as flow is evoked bilaterally, remains elevated as long as the stimulus is present, and an attenuation does not ensue, a BP increase occurs comparably to those observed in NVC studies (Caldas et al. 2018, Giller et al. 2000, Llwyd et al. 2017, Maggio et al. 2013, Nikolic et al. 2015). In contrast to these reports on NVC, however, our continuous motor task showed changes in the LF range $(\% / \mathrm{mmHg})$ and in the VLF range (phase) which are consistent with a disturbed dynamical CA (dCA, Zhang et al.1998, Panerai et al. 1999, Panerai et al. 2001, Serrador et al. 2005). At least in the right MCA, the vessel supplying the cortical areas in which the movement is primarily generated, CVR decreased which can be interpreted as a vasodilation. The CVR decrease seems in agreement with current concepts of neurovasal interaction derived from functional magnetic resonance imaging and from near infrared studies (Huber et al. 2017, Petridou et al. 2017, Schmid et al. 2017): with the beginning of the task a vasodilation occurs which leads to an increase in cerebral blood volume and an increase in the concentration of oxygenated blood which is considered to represent an increase in CBF. When such a vasodilation is induced by $\mathrm{CO}_{2}$, in $\mathrm{dCA}$ the vasodilatory response consists usually of a phase decrease while gain remains not significantly changed (Müller et al. 2016, Panerai et al. 1999, Zhang et al. 1998). Thus, the phase decrease findings in our population could be the result of vasodilation. However, when BP is pharmacologically increased rapidly, dCA's response has been reported to consist of a decrease in both phase and gain accompanied by a CVR increase (Zhang et al. 2009). Our findings with phase and gain decreases would then hint more in the direction of a BP related response with CVR decrease indicating some additional regional regulation.

The other variable to influence dCA is $\mathrm{ETCO}_{2}$ change. An $\mathrm{ETCO}_{2}$ decrease as recorded in our subjects leads usually to a phase increase and to a gain decrease (Birch et al. 1995, Müller et al. 2003). This is contrary to what we have found. An exercise induced lactate acidosis drives a compensatory hyperventilation with the result that dCA's phase and gain were reported unchanged (Ogoh et al. 2007). Thus, $\mathrm{ETCO}_{2}$ decrease due to hyperventilation might have nothing to do with the dCA changes.

The BP rise in our subjects could be due to the (most likely exercise induced) heart rate increase or be a result of the brain's metabolic demands. It is beyond our data to clarify whether the dCA changes are primarily 
due to the metabolic demands or due to the BP increase. Maybe a study comparable to ours which includes an observation of the metabolic changes in the brain, e.g. by using NIRS devices able of recording cytochromeoxidase changes (Obrig et al. 2000) could be of help for this purpose. Such a study might be relevant especially when patients are included (see next paragraph).

Our phase and gain findings could be considered a disturbed dCA induced by performing repetitive arm movements. This movement induced disturbed CA state will interfere in many stroke patients with a preexisting CA condition which by itself is the combined result of an elevated BP, the effect of cerebral ischemia (Llwyd et al. 2018, Reinhard et al. 2012) and/or an unstable circulatory response induced by orthostatic stress (Mitis et al. 2006, Serrador et al. 2005). In clinical practice, in most stroke patient's systolic BP values until $180 \mathrm{~mm} \mathrm{Hg}$ are tolerated. But high BP handicaps $\mathrm{dCA}$ in several conditions: when it is rapidly increased (Zhang et al. 2009), when BP is newly diagnosed before treatment is sufficient (Serrador et al. 2005, Zhang et al. 2007), and in patients with long lasting chronic high BP even when BP is sufficiently treated (Müller et al. 2018). Hence, one future question is whether all disturbances will add up, and whether a risk for the patient will result.

\section{Our study has limitations}

With TF estimates we used strict linear modeling to assess the relationship between BP and CBFV. This kept nonlinear and nonstationary aspects of the system unconsidered (Castro et al. 2017, Giller and Mueller 2003, Placek et al. 2017). All nonlinear approaches showed that the coefficient of variance as a sign of the models quality or analog measures become smaller compared to the strict linear models indicating that these models were likely more precise. However, in terms phase, gain or impulse response as measure of comparison such models did not exhibit large differences from linear differential equations models (Kouchakpour et al. 2014, Marmarelis et al. 2014, Meel-van den Abeelen et al. 2014, Panerai 1999a, Smirl et al. 2015, Panerai et al. 2001). Regarding non-stationarity present in the data, recordings over time periods of several minutes can average out non-stationary effects with the result that time-variant models and time-invariant models produce close results (Kouchakpour et al. 2010, Marmarelis et al. 2014, Nikolic et al. 2015, Placek et al. 2017).

We used CBFV instead of CBF. The velocity signal depends strongly on the vessel's diameter and on multiple other influences apart from $\mathrm{BP}$, such as $\mathrm{CO}_{2}$, autonomic influences, myogenic and cognitive activity (Panerai et al. 2012, Panerai et al. 2012a, Sohn 1998, Spronck et al. 2012). Nevertheless, when a Doppler signal derived index of cerebral blood flow (flow index) was compared to CBFV, this flow index was shown to increase during the hand grip task but the amount of increase was less high compared to the velocity signal (Giller et al. 2000).

We suggest that $\mathrm{ETCO}_{2}$ at rest reflects blood partial $\mathrm{CO}_{2}$ content, a relationship that might be less close and more variable while exercising (Brys et al. 2003, JØrgensen et al. 1992, Ogoh et al. 2007, Robbins et al. 1990). This could be relevant to explain the transfer function result differences between the two cycling studies and our investigation because $\mathrm{CO}_{2}$ reacts slowly and amounts for a considerable fraction of CBFV variations, and hence spectral density, in the LF and VLF range (Kouchakpour et al. 2010, Mitsis et al. 2006, Panerai et al. 2012, Panerai et al. 2012a).

\section{Conclusions}

Our findings suggest that CA adapt to a continuous motor task by modulating CVR, gain and phase. However, the observed changes could also be considered a CA impairment. BP elevation might be a cofactor to be considered. Whether this is of relevance for motor recovery e.g. after stroke needs further investigation.

\section{Conflict of Interest}

There is no conflict of interest.

\section{Acknowledgements}

We gratefully thank Prof RS Smith, Automatic Control Laboratory, ETH Zürich, for his helpful comments on transfer function analysis.

\section{References}

BIRCH AA, DIRNHUBER MJ, HARTLEY-DAVIES R, IANNOTTI F, NEIL-DWYER G: Assessment of autoregulation by means of periodic changes in blood pressure. Stroke 26: 834-837, 1995. 
CALDAS JR, PANERAI RB, SALINET ASM, SENG-SHU E, FERREIERA GSR, CAMARA L, PASSOS RH, GALAS FRBG, ALMEIDA JP, NOGUEIRA RC, DE LIMA OLIVEIRA M, ROBINSON TG, HAJJAR LA: Dynamic cerebral autoregulation is impaired during submaximal isometric handgrip in patients with heart failure. Am J Physiol Heart Circ Physiol 315: H254-H261, 2018.

CASTRO P, FREITAS J, SANTOS R, PANERAI R, AZEVEDO E: Indexes of cerebral autoregulation do not reflect impairment in syncope: insights from head-up tilt test of vasovagal and autonomic failure subjects. Eur J Appl Physiol 117: 1817-1831, 2017.

CHI N-F, HU H-H, WANG C-Y, CHAN L, PENG C-K, NOVAK V, HU C-J: Dynamic cerebral autoregulation is an independent functional outcome predictor of mild acute ischemic stroke. Stroke 49: 2605-2611, 2018.

CLAASSEN JA, MEEL-VAN DEN ABEELEN AS, SIMPSON DM, PANERAI RB: International Cerebral Au-toregulation Research Network (CARNet). Transfer function analysis of dynamic cerebral auto-regulation: A white paper from the International Cerebral Autoregulation Research Network. J Cereb Blood Flow Metab 36: 665-680, 2016.

COLEMAN ER, MOUDGAL R, LANG K, HYACINTH HI, AWOSIKA OO, KISSELA BM, FENG W: Early rehabilitation after stroke: a narrative review. Curr Atheroscler Rep (November 7, 2017). doi 10.1007/s11883017-0686-6, 2017.

GILLER CA, GILLER AM, COOPER CR, HATAB MR: Evaluation of the cerebral hemodynamic response to rhythmic handgrip. J Appl Physiol 88: 2205-2213, 2000.

GILLER CA, MUELLER M: Linearity and non-linearity in cerebral hemodynamics. Med Eng Phys 25: 633-646, 2003.

HARPER SL, BOHLEN HG, RUBIN MJ: Arterial and microvascular contributions to cerebral cortical au-toregulation. Am J Physiol 246: H17-H24, 1984.

HUBER, ULUDAG K, MÖLLER HE: Non-BOLD contrast for laminar fMRI in humans: CBF, CBV, and CRMO2. NeuroImage http://dx.doi.org/10.1016/j.neuroimage.2017.07.041, 2017.

JøRGENSEN LG, PERKO M, HANEL B, SCHROEDER TV, SECHER NH: Middle cerebral artery flow velocity and blood flow during exercise and muscle ischemia in humans. $J$ Appl Physiol 72: 1123-1132, 1992.

KONTOS HA, WIE EP, NAVARI RM, LEVASSEUR JE, ROSENBLUM WI, PATTERSON JL: Responses of cerebral arteries and arterioles to acute hypotension and hypertension. Am J Physiol 234: H371-H383, 1978.

KOUCHAKPOUR H, ALLEN R, SIMPSON DM: Nonlinear, multiple-input modeling of cerebral autoregulation using Volterra Kernel estimation. Conf Proc IEEE Eng Med Biol Soc 2010: 2375-2378, 2010.

LEENDERS KL, PERANI D, LAMMERTSMA AA, HEATHER JD, BUCKINGHAM P, HEALY MJ, GIBBS JM, WISE RJ, HATAZAWA J, HEROLD S: Cerebral blood flow, blood volume and oxygen utilization. Normal values and effect of age. Brain 113: 27-47, 1999.

LI Z, ZHANG X, WANG K, WEN J: Effects of early mobilization after acute stroke: a meta-analysis of randomized control trials. J Stroke Cerebrovasc Dis 27: 1326-1337, 2018.

LLWYD O, PANERAI RB, ROBINSON TG: Effects of dominant and non-dominant passive arm manoeuvres on the neurovascular coupling response. Eur J Appl Physiol 117: 2191-2199, 2017.

LLWYD O, SALINET ASM, PANERAI RB, LAM MY, SAEED NP, BRODIE F, BOR-SENG-SHU, ROBINSON TG, NOGUEIRA RC: Cerebral haemodynamics following acute stroke: effects of stroke severity and stroke subtype. Cerebrovasc Dis Extra 8: 80-89, 2018.

MAGGIO P, SALINET ASM, PANERAI RB, ROBINSON TG: Does hypercapnia-induced impairment of cerebral autoregulation affect neurovascular coupling? A functional TCD study. J Appl Physiol 115: 491-497, 2013.

MARMARELIS VZ, SHIN DC, ORME M, ZHANG R: Time-varying modeling of cerebral hemodynamics. IEEE Trans Biomed Eng 61: 694-704, 2014.

MEEL-VAN DEN ABEELEN ASS, SIMPSON D, ZHANG R, TARUMI T, RICKARDS CA, PAYNE S, MITSIS GD, KOSTOGLOU K, MARMARELIS V, SHIN D, TZENG Y-C, AINSLIE PN, GOMMER E, MÜLLER M, DORADO AC, SMIELEWSKI P, YELICICH B, PUPPO C, LIU X, CZOSNYKA M, WANG C-Y, NOVAK V, PANERAI RB, CLAASSEN JAHR: Between-center variability in transfer function analysis: a widely used method for linear quantification of the dynamic pressure-flow relation: the CARnet bootstrap study. Med Biol Eng 36: 620-627, 2014. 
MITSIS GD, ZHANG R, LEVINE BD, MARMARELIS VZ: Cerebral hemodynamics during orthostatic stress assessed by nonlinear modeling. J Appl Physiol 101: 354-366, 2006.

MÜLLER M, BIANCHI O, ERÜLKÜ S, STOCK C, SCHWERDTFEGER K; HOMBURG TRAUMATIC BRAIN INJURY GROUP. Changes in linear dynamics of cerebrovascular system after severe traumatic brain injury. Stroke 34: 1197-1202, 2003.

MÜLLER MW, ÖSTERREICH M: A comparison of dynamic cerebral autoregulation across changes in cerebral blood flow velocity for 200 s. Front Physiol 5: 327, 2014. doi: 10.3389/fphys.2014.00327

MÜLLER M, ÖSTERREICH M, MÜLLER A, LYGEROS L: Assessment of the brain's macro- and micro-circulatory blood flow responses to $\mathrm{CO}_{2}$ via transfer function analysis. Front Physiol 7: 162, 2016. doi: 10.3389/fphys.2016.00162

MÜLLER M, ÖSTERREICH M, VON HESSLING A, SMITH RS: Incomplete recovery of cerebral blood flow dynamics in sufficiently treated high blood pressure. J Hypertens 37: 372-379, 2019. doi: 10.1097/HJH.0000000000001854

NIKOLIC D, BIRCH AA, PANERAI RB, SIMPSON DM: Assessing cerebral blood flow control from variability in blood pressure and arterial $\mathrm{CO}_{2}$ levels. Conf Proc IEEE Eng Med Biol Soc 2015: 1785-1788, 2015.

OBRIG H, NEUFANG M, WENZEL R, KOHL M, STEINBRINK J, EINHÄUPL K, VILLRINGER A: Spontaneous low frequency oscillations of cerebral hemodynamics and metabolism in human adults. Neuroimage 12: 623-639, 2000.

OGOH S, DALSGAARD MK, SECHER NH, RAVEN PB: Dynamic blood pressure control and middle cerebral artery mean blood velocity variability at rest and during exercise in humans. Acta Physiol 191: 3-14, 2007.

NOGUEIRA RC, BOR-SENG-SHU E, SANTOS MT, NEGRRAO CE, TEIXEIRA MJ, PANERAI RB: Dynamic cerebral autoregulation changes during sub-maximal handgrip maneuver. Plos One 8: e70821, 2013. https://doi.org/10.1371/journal.pone.0070821.

PANERAI RB, DEVERSON ST, MAHONY P, HAYES P, EVANS DH: Effect of $\mathrm{CO}_{2}$ on dynamic cerebral autoregulation measurement. Physiol Meas 20: 265-275, 1999.

PANERAI RB, DAWSON SL, POTTER JF: Linear and nonlinear analysis of human dynamic cerebral autoregulation. Am J Physiol Heart Circ Physiol 277: H1089-H1099, 1999a.

PANERAI RB, DAWSON SL, EAMES PJ, POTTER JF: Cerebral blood flow velocity response to induced and spontaneous sudden changes in arterial blood pressure. Am J Physiol Heart Circ Physiol 280: H2162-2174, 2001.

PANERAI RB, EYRE M, POTTER F: Multivariate modeling of cognitive-motor stimulation on neurovascular coupling: transcranial Doppler used to characterize myogenic and metabolic influences. Am J Physiol Regul Integr Comp Physiol 303: R395-R407, 2012.

PANERAI RB, SALINET ASM, ROBINSON TG: Contribution of arterial blood pressure and $\mathrm{PaCO}_{2}$ to the cerebrovascular responses to motor stimulation. Am J Physiol Heart Circ Physiol 302: H459-H466, 2012 a.

PAULSON OB, HASSELBALCH SG, ROSTRUP E, KNUDSEN GM, PELLIGRINO D: Cerebral blood flow response to functional activation. J Cereb Blood Flow Metab 30: 2-14, 2010.

PETRIDOU N, SIERO JCW: Laminar fMRI: what can the time domain tell us. Non-BOLD contrast for laminar fMRI in humans: $\mathrm{CBF}, \mathrm{CBV}$, and $\mathrm{CMR}_{\mathrm{O} 2}$. NeuroImage 197: 742-760, 2017. http://dx.doi.org/10.1016/j.neuroimage.2017.07.041

PLACEK MM, WACHEL P, ISKANDER DR, SMIELEWSKI P, URYGA A, MIELCZAREK A, SZCZEPAŃSKI TA, KASPROWICZ M: Applying time-frequency analysis to assess cerebral autoregulation during hypercapnia. PLoS ONE 12: e0181851, 2017. https://doi.org/10.1371/ journal.pone.0181851

POWERS WJ: Cerebral hemodynamics in ischemic cerebrovascular disease. Ann Neurol 29: 231-240, 1991.

REINHARD M, RUTSCH S, LAMBECK J, WIHLER C, CZOSNYKA M, WEILLER C, HETZEL A: Dynamic cerebral autoregulation associates with infarct size and outcome after ischemic stroke. Acta Neurol Scand 125: $156-162,2012$. 
RIVERA-LARA L, ZORRILLA-VACA A, GEOCADIN R, ZIA W, HEALY W, THOMPSON R, SMIELEWSKI P, CZOSNYKA M, HOGUE CW: Predictors of outcome with cerebral autoregulation monitoring: a systematic review and meta-analysis. Crit Care Med 45: 695-704, 2017.

ROBBINS PA, CONWAY J, CUNNINGHAM DA, KHAMNEI S, PATERSON DJ: A comparison of indirect methods for continuous estimation of arterial $\mathrm{PCO}_{2}$ in men. $J$ Appl Physiol 68: 1727-1731, 1990.

SALINET ASM, ROBINSON TG, PANERAI RB: Active, passive and motor imagery paradigms: component analysis to assess neurovascular coupling. $J$ Appl Physiol 114: 1406-1412, 2013.

SCHMID F, BARRETT MJP, JENNY P, WEBER B: Vascular density and distribution in neocortex. Neuroimage 197: 792-805, 2017. doi: 10.1016/j.neuroimage.2017.06.046

SERRADOR JM, SOROND FA, VYAS M, GAGNON M, ILOPUTAIFE ID, LIPSITZ LA: Cerebral pressure-flow relations in hypertensive elderly humans: transfer gain in different frequency domains. $J$ Appl Physiol 98: 151-159, 2005.

SMIRL JD, HOFFMANN K, TZENG Y-C, HANSEN A, AINSLIE PN: Methodological comparison of active- and passive-driven oscillations in blood pressure, implications for the assessment of cerebral pressure-flow relationships. J Appl Physiol 119: 487-501, 2015.

SOHN YH: Cerebral hemodynamic changes induced by sympathetic stimulation tests. Yonsei Med J 39: 322-327, 1998.

SPRONCK B, MARTENS EGHJ, GOMMER ED, VAN DE VOSSE FN: A lumped parameter model of cerebral blood flow control combining cerebral autoregulation and neurovascular coupling. Am J Physiol Heart Circ Physiol 303: H1143-H1153, 2012.

ZHANG R, ZUCKERMAN JH, GILLER CA, LEVINE BD: Transfer function analysis of dynamic cerebral autoregulation in humans. Am J Physiol 274: H233-H241, 1998.

ZHANG R, WITKOWSKI S, FU Q, CLAASSEN JAHR, LEVINE BD: Cerebral hemodynamics after short- and longterm reduction in blood pressure in mild and moderate hypertension. Hypertension 49: 1149-1155, 2007.

ZHANG R, BEHBEHANI K, LEVINE BD: Dynamic pressure-flow relationship of the cerebral circulation during acute increase in arterial pressure. $J$ Physiol 587: 2567-2577, 2009. 